\title{
Antipsychotic drugs and diabetes-an application of the Austin Bradford Hill criteria
}

Received: 2 December 2005 / Accepted: 2 March 2006 / Published online: 13 May 2006

C) Springer-Verlag 2006

\begin{abstract}
There is concern that antipsychotic drugs cause diabetes. Although there has been an explosion in the quantity of literature about this subject, it remains confusing and inconsistent. To assess whether the association between antipsychotic drugs and diabetes is causative, we applied the Austin Bradford Hill criteria to the available evidence. In support of a causative relationship, there is temporality for some cases of diabetes, and there is a biologically plausible explanation. The causative link between antipsychotic drugs and diabetes is coherent with our understanding of diabetes and there are other analogies. However the strength of association is weak, there is lack of consistency or specificity, and there is little evidence to support a biological gradient. We should therefore conclude that the evidence surrounding a causative link between antipsychotic drugs and diabetes is inconclusive. Moreover, the risk is probably low and the attributable risk of developing diabetes is greater for traditional risk factors such as family history, ethnicity, obesity and ageing than it is for receiving an antipsychotic drug. Consequently, the majority of patients receiving second-generation antipsychotics will not develop diabetes as a result of their medication.
\end{abstract}

Electronic Supplementary Material Supplementary material is available for this article at http://dx.doi.org/10.1007/s00125-0060279-3

R. I. G. Holt $(\bowtie)$

Endocrinology \& Metabolism Subdivision,

Developmental Origins of Health and Disease Division,

School of Medicine, University of Southampton,

Southampton, UK

e-mail: righ@soton.ac.uk

Tel.: +44-23-80794665

Fax: +44-23-80794945

R. C. Peveler

Community Clinical Sciences Division,

School of Medicine, University of Southampton,

Southampton, UK
Keywords Antipsychotic - Association - Causation · Diabetes

Abbreviations RCT: randomised controlled trial . SMI: severe mental illness

\section{Introduction}

The prevalence of diabetes is higher among people with severe mental illness (SMI) than among the general population, but the underlying reasons for this association remain controversial [1]. While it is likely that there are multiple mechanisms, some of the newer second-generation antipsychotic drugs have been singled out as the major cause of the diabetes in this patient group [2].

The introduction of first-generation or 'typical' antipsychotic medication in the 1950s transformed the lives of many people with SMI, but was marred by the development of disabling and stigmatising extrapyramidal movement disorders. More recently 'atypical' or second-generation antipsychotic drugs have been advocated as first-line treatment for SMI because of their improved efficacy and side effect profile. However, recent concerns about the association between diabetes and second-generation antipsychotics have left psychiatrists wondering whether the move towards secondgeneration antipsychotics has merely led to a substitution of one set of side effects for another, possibly resulting in an overall deterioration in their patients' physical health.

The marketing of second-generation antipsychotics is highly competitive because these products generate significant income for their respective manufacturers; currently sales of antipsychotics worldwide yield over $\$ 8$ billion annually. Until recently there were no studies that differentiated the drugs on the basis of efficacy, and so much of the marketing effort focussed on differentiating one product from another by virtue of differing adverse event profiles [3, 4]. Unjustified concerns about the risk of diabetes and other metabolic side effects may lead to patients being denied effective treatment, so it is crucial 
that we have a clear understanding of any causative relationship between the drugs and diabetes. The literature on this area remains confusing and inconsistent, and many psychiatrists are turning to diabetes specialists for advice.

\section{The sources of evidence linking antipsychotic drugs and diabetes}

Evaluation of the data regarding antipsychotic drugs is challenging because of the underlying two- to three-fold increased risk of diabetes among people with SMI [1]. This increased prevalence results from hereditary and environmental factors, such as less healthy lifestyles. Much of the increased risk can be ascribed to traditional diabetic risk factors such as family history, physical inactivity and poor diet, while there is evidence that SMI itself also increases the risk of diabetes [5-8]. Any data concerning the link between antipsychotics and diabetes must therefore give due consideration to other potentially confounding factors [2].

There are several sources of evidence to consider, including case reports and drugs safety studies, observational analytical studies and experimental analytical studies. It is important to appreciate the strengths and weaknesses of the different types of report.

Case reports are descriptive and may provide evidence of temporality. They can never provide an estimate of the size of risk when applied to the wider population, and so are best used to generate hypotheses underlying an association that can be tested with observational or experimental studies. Drug safety studies are usually large series of case reports. While they begin to address the size of association, they cannot be used to prove causation, as there is no control.

Observational analytical studies can be divided into three main types: cross-sectional studies, case-control studies and cohort studies. Cross-sectional studies are the weakest methodologically but are the easiest to perform. The disease prevalence, for example diabetes, is observed in different groups of individuals, for example those taking different antipsychotic drugs, and the relative frequency of disease is estimated in exposed and unexposed groups. Although these studies will describe how common diabetes is in people receiving antipsychotics, they are unable to determine temporality and therefore cannot determine which outcome occurred first. Logistic regression analysis can be used to determine odds ratios and confidence intervals for the exposure.

Case-control studies are retrospective studies in which diabetes rates are observed in those exposed to different antipsychotic drugs. The rates are compared with those of an unexposed control group that is matched for potentially confounding risk factors, and odds ratios calculated.

Cohort studies take groups of individuals and follow them over a period of time, either prospectively or retrospectively to determine how many subjects exposed to different antipsychotics develop diabetes. Incident diabetes rates can be determined and a relative risk between those taking or not taking antipsychotics can be calculated. Although diabetes is a common chronic disease, the incidence is low and so large numbers must be followed for several years for the study to be successful. It is important that there should be sufficient cases to prevent the study from being underpowered, which frequently happens in studies examining diabetes and antipsychotics.

Observational studies are limited by their naturalistic design. As treatment assignments are not random, the results may be confounded by factors associated with the choice of medication, for example disease severity, or with the risk of diabetes [1]. Most studies are also limited in that they only consider patients treated pharmacologically and therefore miss patients treated by diet alone.

Screening for diabetes varies between different agents, with patients receiving second-generation antipsychotics being much more likely to be screened than those receiving 'typical' drugs $[9,10]$. This is important because as many as $70 \%$ of cases of diabetes in patients with schizophrenia are undiagnosed, and only through a systematic screening programme will all new cases of diabetes be identified [11].

Finally there may be inadequate and incomplete information on, and knowledge of all relevant confounders. Pharmaco-epidemiological studies mainly rely on the analysis of computerised databases of patients treated in various organisations and are limited by the quality of clinical data recorded. Many recognised risk factors for diabetes are not always recorded in the databases, and thus most studies are not controlled for age, race, diet, physical activity, family history or polypharmacy [2].

Experimental analytical studies, such as the prospective, double-blind, randomised controlled trial (RCT), are often considered to be the 'gold standard' for determining cause and effect, such as the efficacy of a drug. Prospective studies examining glucose abnormalities in patients with SMI have begun to appear, but details remain sketchy. Nevertheless these studies are useful in examining the association between diabetes and antipsychotics, because patients are screened for glycaemic abnormalities according to a set protocol and randomisation minimises treatment assignment bias. Placebo studies are particularly interesting, as they allow differentiation between drug effects and the other aspects of treatment.

The position of the double-blind RCT as 'gold standard' may not be appropriate for drug safety studies. There are many examples of observational studies that have made valuable contributions to post-marketing drug monitoring in real-life patients, identifying findings that were not picked up in the restricted setting of an RCT.

Caution should therefore be exercised for a number of reasons. First most RCTs involving antipsychotics were not designed to evaluate side effects [1]. The studies were powered to examine efficacy and all of them are underpowered for the study of side effects. Moreover, the inclusion criteria for such studies are determined by mental illness and not by adverse effects, and so there may be substantial differences in diabetic risk between groups; at best the results are examined as a post hoc analysis. The collection of safety data has not always been of the highest 
quality; in many studies only a subset of patients had blood tests, and these have often combined fasting and random blood samples because of the difficulties of obtaining fasting samples from patients with psychosis. The duration of trials is frequently too short, with most lasting less than 1 year. This may reflect the frequency with which patients change their antipsychotic medication, but is probably too short to evaluate a longer effect on diabetes risk. Finally very few studies are undertaken in treatment-naïve patients, so there may be a carry-over effect from previous treatments that could also affect diabetes risk.

In preparing this review, we considered papers from each category. We undertook an electronic search of the PubMed and Medline databases using the key words 'diabetes' or 'hyperglycaemia' with 'schizophrenia', 'antipsychotic drug' and each individual antipsychotic drug name. Further articles were found through hand searches of the reference lists contained within these papers.

\section{The Austin Bradford Hill criteria for causation}

In 1965, Sir Austin Bradford Hill, emeritus professor of statistics at the University of London, published one of the most important papers on the epidemiological basis of disease causation, in which he described the aspects of an association that needed to be considered when deciding whether the likely interpretation of any association is causation (Table 1) [12]. These aspects are now commonly referred to as the Austin Bradford Hill criteria for causal association and have been widely applied by epidemiologists and others when addressing the causation of disease in a broad range of situations. In this paper we will examine the nine Austin Bradford Hill criteria to gain a further understanding about the association between antipsychotic drugs and diabetes, according to the proposal of Shakir and
Layton [13]. The review will not set out in detail all of the evidence which has been reviewed by us previously $[1,2]$, but where novel data have been published we will draw attention to them. We hope that we will enable evidencebased prescribing of second-generation antipsychotic drugs and demonstrate the utility of the Bradford Hill criteria when considering drug side effects.

\section{Strength of association}

'A strong association is more likely to be causal than a weak association and is less likely to be explained by unrelated biases.'

In epidemiological terms, a relative risk of less than two is considered to indicate a weak association, while greater than three is a strong association. This creates a challenge when the applying this criterion to drug side-effects as a high risk of a serious side effect is likely to have prevented a drug reaching the market.

Several approaches, predominantly the use of observational data, have been adopted to examine the risk of diabetes with different antipsychotics. Two themes emerge from the observational studies. First, treatment with any antipsychotic is associated with more diabetes than no treatment (Electronic Supplementary Material [ESM], Table 1) [14]. The studies give an increased risk of up to seven times [15], although values between 1.5 to 5 are more common [16-22]. Some of these studies compare psychiatric patients receiving antipsychotic drugs with the general population and therefore may overestimate the risk attributable to the drug because the general population is an inappropriate control group. The rates of diabetes are increased in schizophrenic populations and therefore there may be alternative explanations for the increased risk [2]. It

Table 1 Explanation of the Austin Bradford Hill criteria for determining whether an association is causative

\begin{tabular}{|c|c|c|}
\hline Criteria & Meaning & Comments \\
\hline Strength & $\begin{array}{l}\text { The risk is so large that we can easily rule out } \\
\text { other factors }\end{array}$ & $\begin{array}{l}\text { Most serious adverse drugs effects are likely to have weak association only } \\
\text { because a high risk of a serious side effect would have prevented a drug } \\
\text { reaching the market }\end{array}$ \\
\hline Consistency & $\begin{array}{l}\text { The results have been replicated by different } \\
\text { researchers and under different conditions }\end{array}$ & Side effects in small but high-risk groups may lead to inconsistent results \\
\hline Specificity & $\begin{array}{l}\text { The exposure is associated with a specific } \\
\text { disease rather than a wide range of diseases }\end{array}$ & Most drugs cause multiple side effects \\
\hline Temporality & The exposure preceded the disease & \\
\hline $\begin{array}{l}\text { Biological } \\
\text { gradient }\end{array}$ & $\begin{array}{l}\text { Increasing exposure is associated with } \\
\text { increasing risks of disease }\end{array}$ & $\begin{array}{l}\text { The dose response for a side effect may not be the same as for the drug's } \\
\text { indication }\end{array}$ \\
\hline Plausibility & $\begin{array}{l}\text { There is a credible scientific mechanism that can } \\
\text { explain the association }\end{array}$ & \\
\hline Coherence & $\begin{array}{l}\text { The association is consistent with the natural } \\
\text { history of the disease }\end{array}$ & \\
\hline $\begin{array}{l}\text { Experimental } \\
\text { evidence }\end{array}$ & $\begin{array}{l}\text { An intervention shows results consistent with } \\
\text { the association }\end{array}$ & Most RCTs are powered to evaluate efficacy and not side effects \\
\hline Analogy & $\begin{array}{l}\text { There are similar results that we can draw a } \\
\text { relationship to }\end{array}$ & \\
\hline
\end{tabular}


is most appropriate to compare patients with SMI receiving therapy or no therapy, but these studies are hard to perform because most patients will have received treatment at some point during their illness.

The second theme is that treatment with secondgeneration antipsychotics is associated with more diabetes than treatment with a conventional antipsychotic [14]. These studies show that the strength of the association is smaller with most studies showing hazard ratios of less than $1.5[2,17,21,23-36]$. These studies may underestimate any risk, as they assume that conventional antipsychotics have a neutral effect on diabetes. The confidence intervals for the risks are frequently high because of the small numbers of cases of diabetes.

One study, which followed almost 60,000 patients from the Veterans Administration over a follow-up period of 12 28 months, found that $7.3 \%$ of patients were diagnosed with diabetes, giving an annualised incidence rate for diabetes of $4.4 \%$ [31]. There was a slightly higher rate of diabetes for users of clozapine and olanzapine, but the risks associated with quetiapine and risperidone were not statistically significantly different from conventional antipsychotic drugs. The authors then estimated the attribut- able risk of diabetes associated with atypical antipsychotics compared with conventional drugs, defining it as the estimated proportion of patients taking each drug who would not have developed diabetes if they had instead been taking conventional antipsychotics. This ranged from $0.05 \%$ for risperidone to $2.03 \%$ for clozapine, indicating that the absolute excess risk associated with secondgeneration antipsychotics is probably low [31].

Not all studies have shown an excess risk [28, 30] and one US study of 7,381 privately insured patients with SMI, which identified 339 new cases of diabetes between January 1999 and December 2000 and an annualised incidence rate of $4.7 \%$, showed a decrease in diabetes risk with risperidone with no difference in the risk for olanzapine, clozapine and quetiapine [33].

The reported rates of incident diabetes are much lower among UK patients with SMI than in US American populations and have been reported to be less than $1 \%[21$, 37]. At times this low incidence rate has led to incongruous results. For example in the Koro study of 21,145 patients with SMI, undertaken between June 1997 and September 2000 , the diabetes incidence rate among all patients with schizophrenia who were being treated with antipsychotics
Table 2 Details of prospective studies evaluating the risk of diabetes with various antipsychotic drugs
$F B G$ Fasting blood glucose, $R B G$ random blood glucose, $R D B$ randomised double-blind, $R O L$ randomised open label

\begin{tabular}{|c|c|c|c|c|c|}
\hline Drugs & $\begin{array}{l}\text { Number } \\
\text { of subjects }\end{array}$ & $\begin{array}{l}\text { Length of study } \\
\text { (weeks) }\end{array}$ & Glucose measure & Design & Reference \\
\hline Ziprasidone & 136 & 6 & FPG & RDB & [39] \\
\hline Olanzapine & 133 & & & & \\
\hline Ziprasidone & 271 & 28 & FPG & RDB & {$[40]$} \\
\hline Olanzapine & 277 & & & & \\
\hline Haloperidol & 132 & 104 & RPG & RDB & {$[41]$} \\
\hline Olanzapine & 131 & & & & \\
\hline Aripiprazole & 156 & 26 & FPG & RDB & {$[42]$} \\
\hline Olanzapine & 161 & & & & \\
\hline Aripiprazole & 128 & 26 & RPG & ROL & {$[43]$} \\
\hline Olanzapine & 127 & & & & \\
\hline Clozapine & 80 & 52 & $\mathrm{~N} / \mathrm{A}$ & RDB & {$[44]$} \\
\hline Chlorpromazine & 80 & & & & \\
\hline Olanzapine & 26 & 14 & FPG & RDB & {$[45]$} \\
\hline Risperidone & 22 & & & & \\
\hline Haloperidol & 25 & & & & \\
\hline Clozapine & 28 & & & & \\
\hline Placebo & 108 & 26 & FPG & $\mathrm{RDB}$ & {$[1]$} \\
\hline Aripiprazole & 113 & & & & \\
\hline Olanzapine & 224 & 52 & RPG & RDB & {$[47]$} \\
\hline Placebo & 102 & & & & \\
\hline Placebo & 416 & 4 & RPG & RDB & {$[48]$} \\
\hline Haloperidol & 201 & & & & \\
\hline Aripiprazole & 932 & & & & \\
\hline Placebo & 29 & 6 & FPG & RDB & {$[48]$} \\
\hline Aripiprazole & 109 & & & & \\
\hline Olanzapine & 336 & Up to 18 months & Combined FPG and RPG & RDB & [49] \\
\hline Ziprasidone & 185 & & & & \\
\hline Quetiapine & 337 & & & & \\
\hline Risperidone & 341 & & & & \\
\hline Perphenazine & 261 & & & & \\
\hline
\end{tabular}


was only 4.4 per 1,000 person-years [21]. Olanzapine was found to be associated with a 4.4-fold increased risk of diabetes, but this was based on only nine cases of diabetes.

In conclusion, most observational studies involving only mentally ill patients estimate that the excess risk attributable to second-generation antipsychotics is less than two and therefore we must conclude that the strength of association is weak.

\section{Consistency of association}

'Repeated observations of an association in different populations under different circumstances provide additional support for a causal association, although lack of consistency does not rule out a causal association because some effects may be produced only in certain circumstances.'

We have already determined that risk of diabetes with second-generation antipsychotics is probably low and therefore consistency becomes more important. Although the observational studies are consistent in showing that diabetes is more common in those treated with antipsychotics than in those not receiving treatment and in those taking second-generation antipsychotics than in those taking conventional agents, there is no consistency when we examine the retrospective studies that compare one second-generation antipsychotic with another. One of the major concerns about studies of diabetes in patients receiving second-generation antipsychotics is that most studies are funded and co-authored by the pharmaceutical industry. If we consider the large observational pharmacoepidemiological studies comparing second-generation antipsychotics, it would appear that olanzapine is more frequently associated with diabetes than other drugs. However, if only independent studies are examined, this difference disappears and the only consistency we see is that the trial sponsor's drug is found not to be associated with an increased risk of diabetes (ESM, Tables 1 and 2) [38]. This is not to say that the reported studies contain specific methodological flaws, but non-publication of unfavourable results is likely.

In contrast to the observational studies, prospective RCTs are consistent, and find that diabetes rates are not greater in patients receiving any particular antipsychotic. Data about changes in glucose concentrations have been presented from 5,607 patients with schizophrenia or schizophreniform illness recruited in 12 prospective randomised clinical trials, of which 11 were double-blind $[1,39-49]$ (Table 2). Of these studies, eight lasted for at least 6 months and four lasted for more than 1 year. In all of them, there are no significant differences in rates of newly emergent glucose abnormalities between comparator antipsychotics and this is also the case when placebo is included. The raw data, however, are frequently not included and only qualitative statements are made in the safety sections.

Glycosylated haemoglobin has been used in two studies as an integrated measure of changes in blood glucose because of the difficulties in obtaining truly fasting samples in this patient group. In a 1-year, randomised, investigatorblinded study of 45 clinically stable patients with schizophrenia and tardive dyskinesia, $\mathrm{HbA}_{1 \mathrm{c}}$ did not increase during the study and no differences in $\mathrm{HbA}_{1 \mathrm{c}}$ concentrations were reported between the quetiapine and haloperidol treatment groups $[50,51]$

By contrast the recently reported CATIE study, which was a large independent study of 1,493 people with schizophrenia, showed that $\mathrm{HbA}_{1 \mathrm{c}}$ rose by $0.4 \%$ in the patients treated with olanzapine during the 18-month trial, while there was no significant change in $\mathrm{HbA}_{1 \mathrm{c}}$ with any of the other agents [49]. At baseline $11 \%$ of patients had known diabetes, but $16.1 \%$ also had a fasting plasma glucose concentration within the diabetic range when screened for glucose abnormality [52]. As patients with and without diabetes were not dealt with separately for the analysis, it is unclear whether the increase in $\mathrm{HbA}_{1 \mathrm{c}}$ occurred across the whole population or mainly in those with diabetes. The trial does not report the number of new cases of diabetes, but only 2 to $4 \%$ of patients received a new prescription for antidiabetic medication and there was no difference between treatments in this regard.

The differences between the observational and experimental studies appear paradoxical and may reflect the methodologies involved, where the retrospective studies overestimate the risk of diabetes because of treatment assignment bias, screening bias and other confounders, while prospective studies underestimate the risk because of lack of power and short duration of follow-up. Nevertheless the contrast between the retrospective and prospective studies suggests a lack of consistency is apparent.

\section{Specificity of association}

'A cause leads to a single effect not multiple effects, but although the concept of specificity is sometimes helpful, it can be misleading.'

In pharmacovigilance, specificity is also important because drugs cause adverse drug reactions by specific mechanisms. For example, antipsychotics cause hyperprolactinaemia by blockade of the dopamine $\mathrm{D}_{2}$ receptors. Specificity is not always helpful, however, because drugs often have multiple actions and adverse drugs reactions through different mechanisms. The antipsychotics bind to multiple receptors affecting diverse neurological systems and these differ markedly from one antipsychotic to another. Examination of the receptor binding characteristics does not always allow a full understanding of the actions and side effects. For example, all antipsychotics are associated with some weight gain in certain patients, yet no one receptor interaction can account for this side effect. Therefore specificity may not be very helpful in assessing the cause of a side effect. Drugs are not the only agents that do not fulfil this criterion. Cigarette smoking causes a wide range of diseases! 


\section{Temporality of association}

'The cause should precede the effect.'

Here again the evidence is conflicting; case reports showing patients developing diabetes that remits following cessation of treatment, only to re-appear after re-challenge, provide strong evidence of a causative role in these cases. Although these reports can give proof of concept, it is uncertain how far these cases can be extrapolated to the wider SMI population.

On the other hand, the association between diabetes and schizophrenia was recognised at the end of the 19th century, well before the introduction of antipsychotics [53]. Furthermore, it was noted that the insulin doses needed for 'insulin coma therapy' during the 1920s were higher for patients with schizophrenia than for other patients, possibly implying that these individuals were insulin-resistant [54].

It remains unclear whether schizophrenia is associated with diabetes independently of its treatment and associated lifestyle. Studies of Irish first-episode psychosis patients have shown that they are more insulin-resistant and have higher fasting blood glucose concentrations than carefully matched controls [55]. Patients also have more intraabdominal fat and hypercortisolaemia, suggesting that schizophrenia in itself is associated with an increased risk of diabetes [56]. These findings have not been replicated in Chinese and Spanish populations, but methodological and subject differences may explain this discrepancy [57, 58]. Further studies are needed to clarify this area.

It could be argued that if the association is between diabetes and SMI, then patients with type 2 diabetes may be at higher risk of SMI. This has not been observed, but this may merely reflect the earlier onset of psychosis, usually between ages 20 to 30 years, compared with type 2 diabetes. Alternatively, it does not necessarily follow that because one illness predisposes to another, the reverse is also true. For example, patients with type 1 diabetes are more likely to develop other autoimmune diseases such as autoimmune thyroid disease, yet people with autoimmune thyroid disease develop diabetes at similar rates to those seen in the general population. Nevertheless, it will be interesting to observe in the future whether type 2 diabetes proves to be a risk factor for SMI as the age of onset of diabetes falls.

Finally there are case reports of patients with type 1 diabetes whose diabetic control deteriorates with the onset of a new psychosis. Following treatment with antipsychotics, diabetic control is frequently seen to improve [59].

In conclusion, case reports show a temporality that would implicate antipsychotics in disease development in some cases of diabetes. Diabetes risk, however, appears to be increased in patients with SMI in the absence of treatment. Nevertheless, an increased risk of diabetes in patients with SMI would not preclude an additive effect of the antipsychotic.

\section{Biological gradient}

'A biological gradient as demonstrated by a dose-response curve is well known in epidemiology and supports causality.'

Most human studies have not examined dose-response and only one study has shown an increased risk of diabetes with increasing dose of olanzapine [34]. Even this study was far from clear on this issue. The 12 and 24 week data were trends only, and the data only reached statistical significance at 52 weeks. Moreover, the doses compared may not be the doses clinicians are most concerned about when treating patients on high doses, which commonly exceed $20 \mathrm{mg}$ daily among persistently mentally ill patients [60]. When considering surrogate markers, one study has shown that the serum concentration of clozapine and the ratio of olanzapine to $\mathrm{N}$-desmethylolanzapine, one of its metabolites, were correlated with insulin, C-peptide and triglycerides [61].

It may be that the dose-response for diabetes occurs below the therapeutic threshold and so even at the lowest therapeutic dose, the effect on diabetes is maximal.

In summary, there are very few data to support a doseresponse and therefore a biological gradient.

\section{Plausibility}

'Biological plausibility of a hypothesis is another aspect to be considered for causal inference.'

With regard to increasing the risk of diabetes, it seems likely that the antipsychotic drug must either increase insulin resistance, or impair beta cell function, or both.

The association between obesity, weight gain and diabetes is well recognised and this is one potential mechanism by which antipsychotics may increase the risk of diabetes. Evidence from meta-analyses, systematic reviews, individual trials and longer term observational studies has indicated that significant weight gain is seen in many patients receiving psychotropic agents for the treatment of schizophrenia and bipolar disorder. Although no antipsychotic drug can be considered weight-neutral, as weight gain may occur in vulnerable patients during treatment with any atypical antipsychotic, greater mean weight gain does occur with olanzapine and clozapine [62-65].

Despite the marked inter-individual variation in weight gain with antipsychotic drugs, it may be possible to identify those individuals at high risk of weight gain. In a recent analysis, the $15 \%$ of patients who gained more than $7 \%$ body weight in the first 6 weeks of treatment with olanzapine were more likely to gain significant weight gain in the long term [66]. Further studies are needed to determine whether these individuals are at the greatest risk of developing diabetes.

Weight gain does not explain all cases of diabetes. When analysing a series of cases reports, Jin described that nearly $50 \%$ of patients developing diabetes had experienced no 
weight gain during treatment [67]. Furthermore, in the prospective trials, there are no differences in incident diabetes between agents despite marked differences in weight gain.

Antipsychotic-associated weight gain is potentially preventable by the instigation of simple weight management and lifestyle programmes and so it will be instructive to learn in future whether these interventions will ultimately minimise the rates of diabetes in people with SMI [68].

Some clinical studies have evaluated the direct effect of antipsychotic drugs on insulin resistance. Where a change in insulin resistance has been observed in humans, this has been entirely explicable by a change in body weight $[69$, 70]. However, studies in myotubes have shown that olanzapine inhibits insulin signalling [71]. Furthermore, some animal experiments have suggested an immediate deterioration in insulin sensitivity independent of any weight change $[72,73]$.

The prevalence of the metabolic syndrome is increased in patients with SMI and this may partly explain why diabetes is increased in this patient group [52]. As well as an effect on weight, antipsychotics may lead to increases in serum triglyceride concentrations. Clozapine, olanzapine, quetiapine and phenothiazines are more likely to be associated with a rise in triglycerides than other antipsychotics [74]. It would appear that the change in triglycerides is strongly related to weight change.

There is no experimental evidence to support a direct toxic effect of antipsychotics on the pancreas, although insulin secretion may be altered. Experiments in islet cell cultures have shown that clozapine and olanzapine, but not quetiapine, risperidone and ziprasidone, increase insulin release [75]. It is unclear how these findings are to be interpreted during normal physiology as no change in beta cell function has been observed in humans [70]. Nevertheless there are case reports of diabetic ketoacidosis in patients receiving antipsychotics [67]. The cause of the ketoacidosis is unknown; although there is no evidence of autoimmune destruction of the pancreas, a toxic effect cannot be excluded [76].

In summary there is a biologically plausible explanation for the link between antipsychotic drugs and diabetes.

\section{Coherence}

'Any cause and effect interpretation should not conflict with generally known facts of natural history and biology of disease.'

It is well known that the rates of diabetes in patients with SMI are increasing at the same time as the use of secondgeneration antipsychotics is increasing. In fact following the introduction of typical antipsychotics, a marked increase in the rates of diabetes was also observed and the term 'phenothiazine diabetes' appeared in the literature.

An alternative explanation may be that the rate of diabetes in patients with SMI is increasing in line with the general population and any further increase reflects an increased awareness of the need to screen for diabetes in patients with SMI [9].

\section{Experimental evidence}

'Experimental evidence is needed to support a causal inference.'

The randomised controlled trials have been discussed above, but it is clear that studies specifically examining metabolic side effects are needed.

\section{Analogy}

'Inventive scientists can find analogy everywhere. An analogy finds a more elaborate hypothesis about an association under study.'

An analogy showing consistencies with other similar situations could be that other drugs, such as steroids, that cause weight gain are associated with increased rates of diabetes.

\section{Conclusion}

Having reviewed the data using the Austin Bradford Hill criteria, it is clear that some are fulfilled, while others are not. The strength of association is weak, there is lack of consistency or specificity and there is little evidence to support a biological gradient. However temporality for some cases of diabetes exists, and there is a biologically plausible explanation. The causative link between antipsychotics and diabetes is coherent with our understanding of diabetes and there are other analogies.

We should therefore conclude that there may be a causative link between antipsychotics and diabetes. It is also clear, however, that the risk is probably low and the majority of patients receiving second-generation antipsychotics will not develop diabetes as a result of their medication.

By reviewing the data using the Austin Bradford Hill criteria, we can start to identify what kind of further studies are needed to confirm or refute whether antipsychotics cause diabetes. We need to clarify whether only certain patients, for example the rapid weight gainers, rather than the whole population receiving antipsychotics are at increased risk of developing diabetes because of their treatment. We need to find ways of identifying these patients and implementing measures that will prevent or at least delay their diabetes.

The confusion surrounding antipsychotics and diabetes is not unique. Many studies of drug side effects have been reported and have led to substantial public confusion and controversy among the investigators [77]. There are two principle reasons for this. First, the critical-exposure 
variable, i.e. the drug, is generally unstable and not as well defined as other variables such as age or sex. Second, drug-safety research differs from classic epidemiological research in the range of disorders that are of concern. In order to resolve whether antipsychotics cause diabetes, it will be important to design studies in which the drugexposure variable is well defined and relevant to a causal inference and where the diagnosis of diabetes is accurately determined.

This will be challenging, as prospective studies of drugnaive patients over a long period of time ( $3-5$ years) will be needed. The studies should be powered and designed specifically to examine metabolic side effects. These studies may, however, never be possible because of the frequent treatment changes needed by patients with SMI.

We should leave the final word to Sir Austin Bradford Hill, who noted, 'All scientific work is incomplete, whether it be observational or experimental. All scientific work is liable to be upset or modified by advancing knowledge. This does not confer upon us a freedom to ignore the knowledge we already have, or to postpone the action that it appears to demand at a given time.' While future studies may clarify the association between antipsychotics and diabetes, in the meantime it is important that the prime consideration when choosing an antipsychotic should be its ability to treat the patient's mental state, and effective treatment should not be denied because of concerns about metabolic side effects. Nevertheless it is incumbent on health professionals to institute measures that will reduce diabetes risk in this high-risk patient group.

Acknowledgement This paper is based on a lecture given by R. Holt at the meeting of the Association of British Clinical Diabetologists in London on 27 October 2005.

Duality of interest R. Holt has received educational grants and fees for lecturing and consultancy work from Eli-Lilly and GlaxoSmithKline. R. Peveler has received educational grants and fees for lecturing and consultancy work from Eli-Lilly, Astra-Zeneca, Janssen-Cilag, Organon, Synthelabo, GlaxoSmithKline, Pfizer, Wyeth and Lundback.

\section{References}

1. Holt RIG, Bushe C, Citrome L (2005) Diabetes and schizophrenia 2005: are we any closer to understanding the link? J Psychopharmacol 19:56-65

2. Holt RIG, Peveler RC (2006) Anti-psychotic drugs and diabetes. Diabetes Obes Metab 8:125-135

3. Pus PE (2004) Vliv farmaceutickeho prumyslu na vzdelavani lekaru. Psychiatrie (Czech) 8:332

4. Stahl SM (2005) Detecting and dealing with bias in psychopharmacology. PsychEd Up 1:6-7

5. Brown S, Birtwistle J, Roe L, Thompson C (1999) The unhealthy lifestyle of people with schizophrenia. Psychological Med 29:697-701

6. Cheta D, Dumitrescu C, Georgescu M et al (1990) A study on the types of diabetes mellitus in first degree relatives of diabetic patients. Diabetes Metab 16:11-15

7. Mukherjee S, Schnur DB, Reddy R (1989) Family history of type 2 diabetes in schizophrenic patients. Lancet 1:495
8. McCreadie R, Macdonald E, Blacklock C et al (1998) Dietary intake of schizophrenic patients in Nithsdale, Scotland: case-control study. BMJ 317:78-785

9. Taylor D, Young C, Esop R, Paton C, Walwyn R (2004) Testing for diabetes in hospitalised patients prescribed antipsychotic drugs. Br J Psychiatry 185:152-156

10. Citrome LL, Jaffe A, Levine J (2005) Testing for diabetes. Br J Psychiatry $186: 78$

11. Subramaniam M, Chong SA, Pek E (2003) Diabetes mellitus and impaired glucose tolerance in patients with schizophrenia. Can J Psychiatry 48:345-347

12. Hill AB (1965) The environment and disease; association or causation. Proc Royal Soc Med 58:295-330

13. Shakir SA, Layton D (2002) Causal association in pharmacovigilance and pharmacoepidemiology: thoughts on the application of the Austin Bradford-Hill criteria. Drug Saf 25:467-471

14. Haddad PM (2004) Antipsychotics and diabetes: review of nonprospective data. Br J Psychiatry 47(Suppl):S80-S86

15. Gianfrancesco FD, Grogg AL, Mahmoud RA, Wang RH, Nasrallah HA (2002) Differential effects of risperidone, olanzapine, clozapine, and conventional antipsychotics on type 2 diabetes: findings from a large health plan database. J Clin Psychiatry 63:920-930

16. Gianfrancesco F, White R, Wang RH, Nasrallah HA (2003) Antipsychotic-induced type 2 diabetes: evidence from a large health plan database. J Clin Psychopharmacol 23:328-335

17. Buse JB, Cavazzoni P, Hornbuckle K, Hutchins D, Breier A, Jovanovic L (2003) A retrospective cohort study of diabetes mellitus and antipsychotic treatment in the United States. J Clin Epidemiol 56:164-170

18. Gianfrancesco F, Grogg A, Mahmoud R, Wang RH, Meletiche D (2003) Differential effects of antipsychotic agents on the risk of development of type 2 diabetes mellitus in patients with mood disorders. Clin Ther 25:1150-1171

19. Etminan M, Streiner DL, Rochon PA (2003) Exploring the association between atypical neuroleptic agents and diabetes mellitus in older adults. Pharmacotherapy 23:1411-1415

20. Wang PS, Glynn RJ, Ganz DA, Schneeweiss S, Levin R, Avorn J (2002) Clozapine use and risk of diabetes mellitus. J Clin Psychopharmacol 22:236-243

21. Koro CE, Fedder DO, L'Italien GJ et al (2002) Assessment of independent effect of olanzapine and risperidone on risk of diabetes among patients with schizophrenia: population based nested case-control study. BMJ 325:243

22. Kornegay CJ, Vasilakis-Scaramozza C, Jick H (2002) Incident diabetes associated with antipsychotic use in the United Kingdom general practice research database. J Clin Psychiatry 63:758-762

23. Sernyak MJ, Leslie DL, Alarcon RD, Losonczy MF, Rosenheck R (2002) Association of diabetes mellitus with use of atypical neuroleptics in the treatment of schizophrenia. Am J Psychiatry 159:561-566

24. Lund BC, Perry PJ, Brooks JM, Arndt S (2001) Clozapine use in patients with schizophrenia and the risk of diabetes, hyperlipidemia, and hypertension: a claims-based approach. Arch Gen Psychiatry 58:1172-1176

25. Caro JJ, Ward A, Levinton C, Robinson K (2002) The risk of diabetes during olanzapine use compared with risperidone use: a retrospective database analysis. J Clin Psychiatry 63:1135-1139

26. Fuller MA, Shermock KM, Secic M, Grogg AL (2003) Comparative study of the development of diabetes mellitus in patients taking risperidone and olanzapine. Pharmacotherapy 23:1037-1043

27. Smith RC, Lindenmayer JP, Bark N, Warner-Cohen J, Vaidhyanathaswamy S, Khandat A (2005) Clozapine, risperidone, olanzapine, and conventional antipsychotic drug effects on glucose, lipids, and leptin in schizophrenic patients. Int J Neuropsychopharmacol:1-12 
28. Taylor D, Young C, Mohamed R, Paton C, Walwyn R (2005) Undiagnosed impaired fasting glucose and diabetes mellitus amongst inpatients receiving antipsychotic drugs. J Psychopharmacol 19:182-186

29. Citrome LL, Jaffe A, Levine J, Allingham B, Robinson J (2004) Relationship between antipsychotic medication treatment and new cases of diabetes among psychiatric inpatients. Psychiatr Serv 55:1006-1013

30. Barner JC, Worchel J, Yang M (2004) Frequency of new-onset diabetes mellitus and use of antipsychotic drugs among Central Texas veterans. Pharmacotherapy 24:1529-1538

31. Leslie DL, Rosenheck RA (2004) Incidence of newly diagnosed diabetes attributable to atypical antipsychotic medications. Am J Psychiatry 161:1709-1711

32. Ollendorf DA, Joyce AT, Rucker M (2004) Rate of new-onset diabetes among patients treated with atypical or conventional antipsychotic medications for schizophrenia. Med Gen Med 6:5

33. Miller EA, Leslie DL, Rosenheck RA (2005) Incidence of newonset diabetes mellitus among patients receiving atypical neuroleptics in the treatment of mental illness: evidence from a privately insured population. J Nerv Ment Dis 193:387-395

34. Lambert BL, Chou CH, Chang KY, Tafesse E, Carson W (2005) Antipsychotic exposure and type 2 diabetes among patients with schizophrenia: a matched case-control study of California Medicaid claims. Pharmacoepidemiol Drug Saf $14: 417-425$

35. Mackin P, Watkinson HM, Young AH (2005) Prevalence of obesity, glucose homeostasis disorders and metabolic syndrome in psychiatric patients taking typical or atypical antipsychotic drugs: a cross-sectional study. Diabetologia 48:215-221

36. Spoelstra JA, Stolk RP, Cohen D et al (2004) Antipsychotic drugs may worsen metabolic control in type 2 diabetes mellitus. J Clin Psychiatry 65:674-678

37. Biswas PN, Wilton LV, Pearcel GL, Freemantle S, Shakir SA (2001) The pharmacovigilance of olanzapine: results of a post-marketing surveillance study on 8858 patients in England. J Psychopharmacol 15:265-271

38. Citrome LL (2004) The increase in risk of diabetes mellitus from exposure to second-generation antipsychotic agents. Drugs Today 40:445-464

39. Simpson GM, Glick ID, Weiden PJ, Romano SJ, Siu CO (2004) Randomized, controlled, double-blind multicenter comparison of the efficacy and tolerability of ziprasidone and olanzapine in acutely ill inpatients with schizophrenia or schizoaffective disorder. Am J Psychiatry 161:1837-1847

40. Kane JM (2003) Oral ziprasidone in the treatment of schizophrenia: a review of short-term trials. J Clin Psychiatry 64 (Suppl 19):19-25

41. Lieberman JA, Tollefson G, Tohen M et al (2003) Comparative efficacy and safety of atypical and conventional antipsychotic drugs in first-episode psychosis: a randomized, double-blind trial of olanzapine versus haloperidol. Am J Psychiatry 160:1396-1404

42. McQuade RD, Stock E, Marcus R et al (2004) A comparison of weight change during treatment with olanzapine or aripiprazole: results from a randomized, double-blind study. J Clin Psychiatry 65(Suppl 18):47-56

43. Bushe C, Holt R (2004) Prevalence of diabetes and impaired glucose tolerance in patients with schizophrenia. Br J Psychiatry (Suppl 47):S67-S71

44. Lieberman JA, Phillips M, Gu H et al (2003) Atypical and conventional antipsychotic drugs in treatment-naive firstepisode schizophrenia: a 52-week randomized trial of clozapine vs chlorpromazine. Neuropsychopharmacol 28:995-1003

45. Lindenmayer JP, Czobor P, Volavka J et al (2003) Changes in glucose and cholesterol levels in patients with schizophrenia treated with typical or atypical antipsychotics. Am J Psychiatry 160:290-296

46. Torbeyns A, Marder S, Carson W et al (2004) Glycaemic control and plasma lipids in long term treatment with aripiprazole. Schizophrenia Res 67(Suppl):S192
47. Beasley CM Jr, Sutton VK, Hamilton SH et al (2003) A doubleblind, randomized, placebo-controlled trial of olanzapine in the prevention of psychotic relapse. J Clin Psychopharmacol 23:582-594

48. Marder SR, McQuade RD, Stock E et al (2003) Aripiprazole in the treatment of schizophrenia: safety and tolerability in shortterm, placebo-controlled trials. Schizophr Res 61:123-136

49. Lieberman JA, Stroup TS, McEvoy JP et al (2005) Effectiveness of antipsychotic drugs in patients with chronic schizophrenia. N Engl J Med 353:1209-1223

50. Emsley R, Turner HJ, Schronen J, Botha K, Smit R, Oosthuizen PP (2005) Effects of quetiapine and haloperidol on body mass index and glycaemic control: a long-term, randomized, controlled trial. Int J Neuropsychopharmacol:1-8

51. Emsley R, Turner HJ, Schronen J, Botha K, Smit R, Oosthuizen PP (2004) A single-blind, randomized trial comparing quetiapine and haloperidol in the treatment of tardive dyskinesia. J Clin Psychiatry 65:696-701

52. McEvoy JP, Meyer JM, Goff DC et al (2005) Prevalence of the metabolic syndrome in patients with schizophrenia: baseline results from the Clinical Antipsychotic Trials of Intervention Effectiveness (CATIE) schizophrenia trial and comparison with national estimates from NHANES III. Schizophr Res 80:19-32

53. Lorenz WF (1922) Sugar intolerance in dementia praecox and other mental disorders. Arch Neurol Psychiatry 8:184-196

54. Appel KE, Farr CB (1929) Blood sugar reaction to insulin in psychoses. Arch Neurol Psychiatry 21:145-148

55. Ryan MC, Collins P, Thakore JH (2003) Impaired fasting glucose tolerance in first-episode, drug-naive patients with schizophrenia. Am J Psychiatry 160:284-289

56. Thakore JH, Mann JN, Vlahos I, Martin A, Reznek R (2002) Increased visceral fat distribution in drug-naive and drug-free patients with schizophrenia. Int J Obes Relat Metab Disord 26:137-141

57. Zhang ZJ, Yao ZJ, Liu W, Fang Q, Reynolds GP (2004) Effects of antipsychotics on fat deposition and changes in leptin and insulin levels. Magnetic resonance imaging study of previously untreated people with schizophrenia. Br J Psychiatry 184:58-62

58. Arranz B, Rosel P, Ramirez N et al (2004) Insulin resistance and increased leptin concentrations in noncompliant schizophrenia patients but not in antipsychotic-naive first-episode schizophrenia patients. J Clin Psychiatry 65:1335-1342

59. Balter J, Mofsen R, Pinninti N (2004) Quetiapine in the successful treatment of psychosis and comorbid brittle diabetes mellitus: a case report. Int J Psychiatry Med 34:259-266

60. Citrome L, Jaffe A, Levine J (2005) Dosing of second-generation antipsychotic medication in a state hospital system. J Clin Psychopharmacol 25:388-391

61. Perry PJ, Argo TR, Carnahan RM et al (2005) The association of weight gain and olanzapine plasma concentrations. J Clin Psychopharmacol 25:250-254

62. Haddad P (2005) Weight change with atypical antipsychotics in the treatment of schizophrenia. J Psychopharmacol 19:16-27

63. Allison DB, Mentore JL, Heo M et al (1999) Antipsychoticinduced weight gain: a comprehensive research synthesis. Am J Psychiatry 156:1686-1696

64. Lambert M, Haro JM, Novick D et al (2005) Olanzapine vs. other antipsychotics in actual out-patient settings: six months tolerability results from the European Schizophrenia Out-patient Health Outcomes study. Acta Psychiatr Scand 111:232-243

65. Potkin SG, Saha AR, Kujawa MJ et al (2003) Aripiprazole, an antipsychotic with a novel mechanism of action, and risperidone vs placebo in patients with schizophrenia and schizoaffective disorder. Arch Gen Psychiatry 60:681-690

66. Kinon BJ, Kaiser CJ, Ahmed S, Rotelli MD, Kollack-Walker S (2005) Association between early and rapid weight gain and change in weight over one year of olanzapine therapy in patients with schizophrenia and related disorders. J Clin Psychopharmacol 25:255-258 
67. Jin H, Meyer JM, Jeste DV (2002) Phenomenology of and risk factors for new-onset diabetes mellitus and diabetic ketoacidosis associated with atypical antipsychotics: an analysis of 45 published cases. Ann Clin Psychiatry 14:59-64

68. Menza M, Vreeland B, Minsky S, Gara M, Radler DR, Sakowitz M (2004) Managing atypical antipsychotic-associated weight gain: 12-month data on a multimodal weight control program. J Clin Psychiatry 65:471-477

69. Sowell M, Mukhopadhyay N, Cavazzoni P et al (2003) Evaluation of insulin sensitivity in healthy volunteers treated with olanzapine, risperidone, or placebo: a prospective, randomized study using the two-step hyperinsulinemic, euglycemic clamp. J Clin Endocrinol Metab 88:5875-5880

70. Sowell MO, Mukhopadhyay N, Cavazzoni P et al (2002) Hyperglycemic clamp assessment of insulin secretory responses in normal subjects treated with olanzapine, risperidone, or placebo. J Clin Endocrinol Metab 87:2918-2923

71. Engl J, Laimer M, Niederwanger A et al (2005) Olanzapine impairs glycogen synthesis and insulin signaling in L6 skeletal muscle cells. Mol Psychiatry 10:1089-1096
72. Ader M, Kim SP, Catalano KJ et al (2005) Metabolic dysregulation with atypical antipsychotics occurs in the absence of underlying disease: a placebo-controlled study of olanzapine and risperidone in dogs. Diabetes 54:862-871

73. Baptista T, Alvarez L, Lacruz A, de Mendoza S, Hernandez L (1999) Glucose tolerance and serum insulin levels in an animal model of obesity induced by sub-acute or chronic administration of antipsychotic drugs. Prog Neuropsychopharmacol Biol Psychiatry 23:277-287

74. Bushe C, Paton C (2005) The potential impact of antipsychotics on lipids in schizophrenia: is there enough evidence to confirm a link? J Psychopharmacol 19:76-83

75. Melkersson K, Jansson E (2005) The atypical antipsychotics quetiapine, risperidone and ziprasidone do not increase insulin release in vitro. Neuro Endocrinol Lett 26:205-208

76. Avram AM, Patel V, Taylor HC, Kirwan JP, Kalhan S (2001) Euglycemic clamp study in clozapine-induced diabetic ketoacidosis. Ann Pharmacotherapy 35:1381-1387

77. Jick H, Garcia Rodriguez LA, Perez-Gutthann S (1998) Principles of epidemiological research on adverse and beneficial drug effects. Lancet 352:1767-1770 